\title{
EXPERIÊNCIA VIVENCIADA POR MÃES DE CRIANÇAS COM INTOLERÂNCIA À LACTOSE*
}

\section{EXPERIENCE FACED BY MOTHERS WHO SONS HAVE LACTOSE'S INTOLERANCE EXPERIENCIA VIVIDA POR LAS MADRES DE NIÑHOS CON INTOLERANCIAA LA LACTOSIS}

\author{
Clarissa Paz Corrêa Porto** \\ Maira Buss Thofehrn ${ }^{\star \star *}$ \\ Afra Suelene de Sousa ${ }^{\star \star \star \star}$

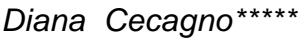

\footnotetext{
* Trabalho Monográfico de conclusão do Curso de Graduação pela Faculdade de Enfermagem e Obstetrícia da Universidade Federal de Pelotas

** Acadêmica de Enfermagem Autora do Trabalho Monográfico

*** Doutora em Enfermagem, Professora da Faculdade de Enfermagem e Obstetrícia da Universidade Federal de Pelotas e Coordenadora do NEPEN.

**** Mestre em Assistência de Enfermagem, Adjunta da Faculdade de Enfermagem e Obstetrícia da Universidade Federal de Pelotas, Chefe do Departamento de Enfermagem (Orientadora).

$\star * * * *$ Enfermeira. Mestre em Enfermagem pela FURG
}

RESUMO. Este trabalho objetivou conhecer a experiência de mães de crianças com diagnóstico de intolerância à lactose (I.L.). O método da pesquisa foi descritivo como do tipo exploratório com abordagem qualitativa. Para a coleta de dados utilizou-se entrevista semi-estruturada, aplicada a três mães de crianças com IL, previamente selecionadas por meio de prontuário médico, de um consultório pediátrico, da Região Sul do Rio Grande do Sul. Após várias leituras dos dados colhidos emergiu o tema central: a experiência vivenciada por mães de crianças com IL. Assim, foi possível desvelar as dificuldades que passam os familiares, especialmente, as mães de crianças com IL, já que os sinais e sintomas podem ser facilmente confundidos com outras patologias. Desta forma, é de fundamental importância que profissionais de enfermagem tenham o devido preparo para identificar a sintomatologia das crianças acometidas por IL para prestarem um cuidado terapêutico, que auxilie na adaptação da criança e da família para essa nova realidade.

PALAVRAS-CHAVE: intolerância a lactose; criança; cuidado.

ABSTRACT. This work aimed to know the experiences by mothers of children with lactose's intolerance (LI) diagnostic. It was qualitative research using half-structuralized interview as a data collection method; therefore three mothers were previously chased by the children's medical record in a pediatric practice, in the South Region of Brazil. After several reading of the collected data a major theme emerged: the experience faced by mothers who sons have LI. So, it was possible to identify the families difficulties especially mothers who children have LI, since the symptoms could be easily confounded with others pathologies. Is important nursing professionals to have skills to identify LI symptoms in order to give adequate therapeutic care helping the children and their family to adapt into new reality.

KEYWORDS: lactose's intolerance; child; care.

RESUMEN. Este Estudio tuvo como objetivo conocer la experiencia de madres de niños con diagnostico de intolerancia a lactosis (IL). El método de investigación fue el abordaje cualitativo-descriptivo del tipo explorador, se utilizo la entrevista seme-estructurada, aplicada a tres madres de niños con IL, previamente seleccionadas por medio de fichas medicas de un consultorio pediátrico de la región sur de Rio Grande do Sul/Brasil. Después de varias lecturas de los dados cogidos, surgió el tema central: La experiencia vivida por madres de niños con IL. Entonces fue posible desvelar las dificultades que pasan los familiares, especialmente, las madres de niños con IL ya que los señales y síntomas pueden ser fácilmente confundidos con otras patologías. Por eso, es de gran importancia, que profesionales de enfermería tengan un preparo debido para identificar la sintomatología de niños acometidos por IL, para suministrar una atención terapéutica que ayude en la adaptación del niño y su familia para esa nueva realidad.

PALABRAS-CLAVE: intolerancia a lactosis; niño; cuidado.

Recebido em: 21/01/2005

Aceito em: 28/07/2005
Maira Buss Thofehrn

Rua Carlos Gomes, 541

96055-450 - Pelotas - RS

Fone: (53) 3273-3116

E-mail: mairabt@ufpel.tche.br 


\section{INTRODUÇÃO}

A intolerância à lactose é a incapacidade do organismo de aproveitar e digerir a lactose, ingrediente característico do leite animal ou derivados. A lactose é um dissacarídeo, ou seja, um "açúcar" constituído por duas unidades básicas: a glicose e a galactose. A intolerância à lactose é resultante da ausência ou deficiência da enzima intestinal denominada lactase. A enzima em questão é responsável pela decomposição da lactose em dois monossacarídeos, as duas unidades básicas já citadas, o que facilita a absorção desse principal "açúcar" do leite, sendo usada como fonte de energia para o organismo. Assim, a intolerância à lactose (IL) produz alterações abdominais e na maioria das vezes, diarréia, que é mais evidente nas primeiras horas seguintes ao seu consumo ${ }^{1 ; 2}$.

Essa reação orgânica, isto é, a intolerância à lactose, caracteriza-se por ser um conjunto de sinais e sintomas que as pessoas apresentam após a ingestão de leite e lactiários, variando a intensidade da intolerância e a resposta perante a ingesta alimentar rica em lactose, em virtude da singularidade de cada ser humano. Além da diarréia, a pessoa pode apresentar dor e distensão abdominal, flatulência, náuseas e vômitos ${ }^{3}$. Cabe esclarecer, porém, que em muitos casos, pode ocorrer dor e distensão abdominal sem diarréia.

Quando a intolerância à lactose se manifesta na criança, a sintomatologia gera angústia nas mães e familiares e normalmente o diagnóstico conclusivo não é realizado de imediato em virtude de outras duas reações orgânicas, que podem ocorrer e que interferem na identificação da intolerância à lactose, isto é, alergia e sensibilidade.

Portanto na trajetória da descoberta e identificação da sintomatologia da intolerância à lactose até o diagnóstico, os aspectos angustiantes referem-se ao choro desesperado de um bebê, sem motivos aparentes, o surgimento da diarréia, sem entender a causa, as queixas constantes de dor abdominal de uma criança, a investigação com exames que na maioria das vezes não conduzem ao diagnóstico conclusivo de imediato. Aparentemente, um diagnóstico tão simples, que pode ser solucionado com a retirada da lactose da dieta alimentar, acaba transformandose em situação estressante, angustiante e traumática para todos os envolvidos, ou seja, criança e familiares.

Escolhi este tema para meu trabalho de conclusão de curso, por ter sido sensibilizada ao passar por todas essas fases de apreensão, incertezas e angústia com minhas duas filhas, pois os sinais e sintomas estavam ali presentes nas crianças, causando desconforto e sofrimento a elas e a mim. Neste processo, me sentia impotente, aguardando os exames, os diagnósticos diferenciais, os posicionamentos da equipe médica. Essa espera gerava sofrimento físico e emocional em mim, como mãe, estudante de enfermagem, e nos demais membros da minha família, ocorrendo desgaste e trauma psicológico, muitas vezes levando ao desequilíbrio da harmonia familiar.

Em face das situações vividas, pude perceber que os profissionais de saúde ainda não possuem o preparo adequado para chegar rapidamente ao diagnóstico de intolerância à lactose. A pouca informação e divulgação quanto à intolerância à lactose determina a falta de preparo mais aprofundado da equipe multiprofissional, ocasionando nas mães e familiares da criança portadora desta patologia insegurança e dificuldade em proporcionar o correto e adequado tratamento.

Resolvi pesquisar a temática em questão para aprofundar e aprimorar meus conhecimentos, pois a intolerância à lactose é problema cada vez mais freqüente e merece atenção especial de todos os profissionais da saúde que lidam com crianças. Visando por parte da equipe médica a um pronto diagnóstico, tratamento correto e precoce e, por parte da equipe de enfermagem, à prestação de um cuidado terapêutico de qualidade, com atenção especial ao sofrimento da criança e de seus familiares. Ainda, fazem-se necessários cuidados específicos por parte dos demais profissionais da saúde, de forma a minimizar as conseqüências da exposição da criança e da família a situações 
desnecessárias, amenizando os traumas psicológicos, freqüentes nas pessoas envolvidas.

O cuidado terapêutico é compreendido como a tarefa profissional, uma ação e um discurso com intenção terapêutica, para resolução dos problemas de saúde das pessoas, tanto no âmbito preventivo e curativo, quanto na reabilitação ${ }^{4}$. No caso desse estudo é um agir com competência profissional que direcione a criança com intolerância à lactose e seus familiares a uma vida saudável. Tendo em vista o que foi abordado, me propus desenvolver este estudo que tem como objetivo: conhecer a experiência de mães de crianças com diagnóstico de intolerância à lactose.

\section{METODOLOGIA}

O estudo caracterizou-se como qualitativo, do tipo exploratório-descritivo. Os critérios de seleção das mães incluíram: ter filhos com idade entre 0 e 12 anos e portadores de diagnóstico de intolerância à lactose. As mães foram selecionadas por meio de prontuários médicos de um consultório pediátrico, da Região Sul do Rio Grande do Sul. A participação na pesquisa foi voluntária, os sujeitos deste estudo concordaram com o uso de gravador durante a entrevista e permitiram que os dados fossem publicados.

Para garantia do sigilo e anonimato, os sujeitos foram identificados por nomes de personagens infantis que os próprios filhos escolheram para suas mães, sendo os seguintes: Hello Kitty (mãe de uma menina de dois anos e onze meses), Moranguinho (mãe de uma menina de dois anos) e Sr. Incrível (mãe de um menino de seis anos).

Os preceitos éticos permearam todo o percurso da pesquisa, em obediência aos princípios contidos no Código de Ética dos Profissionais de Enfermagem ${ }^{5}$, além de atender à Resolução $n .^{0}$ 196/96 do Conselho Nacional de Saúde, que versa sobre as diretrizes para realização de pesquisa com seres humanos ${ }^{6}$. A proposta do estudo foi aprovada pelo Comitê de Ética da Instituição de Ensino local. Após a seleção dos sujeitos e exposto o objetivo do trabalho, os mesmos assinaram o consentimento livre e esclarecido. Às mães entrevistadas foi concedido livre acesso aos dados coletados na pesquisa, que foram obtidos mediante a técnica de entrevista semi-estruturada.

Após a realização das entrevistas, os dados foram transcritos. Por meio de leitura exaustiva dos dados, foram agrupados, confrontados com a literatura consultada, bem como o posicionamento da autora. Assim emergiu um tema central: EXPERIÊNCIA VIVENCIADA POR MÃES DE CRIANÇAS COM INTOLERÂNCIA À LACTOSE.

\section{APRESENTAÇÃO E DISCUSSÃO DOS RESULTADOS}

\section{EXPERIÊNCIA VIVENCIADA POR MÃES DE CRIANÇAS COM INTOLERÂNCIA À LACTOSE}

Os dados mostram que existe uma dificuldade para a identificação diagnóstica da intolerância à lactose, situação que gera angústia nas mães e familiares. A intolerância à lactose pode ser confundida com alergia ou sensibilização, mas essas reações do organismo diferem quanto às conseqüências, desde um mal-estar até o risco de morte ${ }^{7: 8}$.

As mães entrevistadas relataram a dificuldade em encontrar um profissional de saúde que atenda e entenda seus apelos, pois a criança por longo tempo doente traumatiza sua mãe, já que esta se sente impotente, com sentimento de culpa, pelo desequilíbrio emocional gerado por tal situação, como se evidencia nas falas a seguir:

Há um tempo atrás mudei de pediatra [...] me sentia abandonada, ela não dava importância ao que eu estava dizendo, dizia que era uma cólica comum de nenê, que era assim mesmo e que ia passar; mas eu sabia que aquilo não era normal, com meu outro filho não foi assim... (Moranguinho)

Eu procurei ajuda de um homeopata, porque comecei a me desesperar com a dificuldade que ele tinha para evacuar. Inclusive, às vezes, ele evacuava com sangue. O homeopata, além de receitar as homeopatias, receitou também fibras e o meu filho melhorou suas funções intestinais e também o humor, mas não resolveu o problema por inteiro, por ele não ter identificado a intolerância à lactose, tratando apenas da constipação. (Sr. Incrível) 
Os profissionais de saúde, muitas vezes, tratam e cuidam do sintoma momentâneo, por não reunir todos os sinais e sintomas apresentados pela criança ou porque tal sintomatologia pode ficar mascarada, em virtude de serem evidências freqüentes de outras patologias, apresentadas pelas crianças e que são determinadas por vários agentes causadores, levando à dificuldade de identificação da intolerância à lactose.

Percebo que muitos profissionais apresentamse despreparados para lidar com as questões subjetivas, que envolvem mãe-filho e famílias, pois as instituições de ensino pouco direcionam os currículos para o desenvolvimento das habilidades emocionais. As emoções consistem em impulsos para uma ação imediata, para um rápido planejamento que tem o objetivo de manter a vida, mas esse agir está imbricado com a experiência e cultura de cada pessoa ${ }^{9}$. Reforça a necessidade de atentar para a empatia que se constitui num ato de compreensão tão seguro em relação ao outro, quanto a apreensão do significado das palavras contidas em um livro, pois assim como temos a mente racional, também temos a mente emocional.

O cuidado é uma constante no cotidiano de vida da enfermagem e que deve causar, nesses profissionais, a liberação de emoções, tais como alegria, motivação, prazer e um renascer pelas muitas perspectivas que se desvelam, durante a execução de suas ações ${ }^{10}$. A autora alerta que constata na prática da enfermagem a existência do não cuidado, em virtude da dificuldade que alguns profissionais apresentam em compreender a si mesmos, o que dificultando o processo de viver realmente o cuidado à pessoa em sofrimento físico, psíquico e social.

Um aspecto significativo, identificado pelo relato de duas mães entrevistadas, foi a prematuridade de seus filhos.

Ele foi prematuro de oito meses. (Sr. Incrível)

Ela nasceu de oito meses, quando deu alta do hospital tinha 5 dias, no cocô saía umas raias de sangue, o cocô era bem aguado e ela chorava muito de cólica. (Moranguinho)
A criança prematura e os lactentes são os mais vulneráveis, devido à imaturidade funcional e estrutural de sua mucosa intestinal. Os sintomas mais comuns são desconforto e dores abdominais, náuseas e diarréia. A intolerância à lactose pode resultar em sangue nas fezes, anemia, perda de oligoelementos com carências específicas e retardo no desenvolvimento pondero-estatural ${ }^{1}$. Nas falas a seguir foi possível identificar os sintomas característicos de intolerância à lactose.

Ela é magrinha, não se desenvolve direito, sempre foi de baixo peso; por isso também eu acho que ela tem a resistência baixa [...] se queixa sempre de dor na barriga e quase sempre está com diarréia. (Moranguinho)

Foi o pai dele que começou a desconfiar, pois achava o cocô dele muito estranho. Era muito volumoso e também sofria muito para ir aos pés. Ele era muito constipado, mas como eu também tinha esse problema, achei que ele era parecido comigo e não me preocupava tanto. (Sr. Incrível)

Por volta dos dois anos de idade minha filha começou a apresentar manchas pelo corpo do tipo urticária, tinha coceira e tudo e se queixava de dores de barriga. (Hello Kitty)

A intolerância é uma resposta física anormal a um alimento ou aditivo, não é imunológica como no caso da alergia. Infelizmente, às vezes, as crianças são expostas a procedimentos desnecessários, passando por grandes dificuldades, até a descoberta da intolerância à lactose ${ }^{11}$. Conforme se identificou na fala a seguir:

Quando ele sentiu forte dor abdominal, fomos para um pronto-atendimento, lá foi solicitado uma ultra-sonografia e foi descoberto nódulos abdominais. Então, começou nosso tormento. Depois disso, foram feitos vários exames como cintilografia, tomografia e colonoscopia. Os possíveis diagnósticos é que quase nos mataram. Tuberculose intestinal, colite ulcerativa, câncer ou doença de Crown. Então, fomos encaminhados para Porto Alegre, onde ficamos internados 15 dias na ala de crianças com câncer, meu sentimento era desesperador, até que aos 7 dias de internação foi feito então a biópsia abdominal por via aberta, fomos muito bem atendidos 
[...] quando saiu o diagnóstico da biópsia era doença inflamatória de origem alérgica e intolerância à lactose. (Sr. Incrível)

O diagnóstico de intolerância à lactose é baseado na associação da sintomatologia e dos exames laboratoriais, tais como teste oral de tolerância à lactose, do hidrogênio expirado, a medida do $\mathrm{pH}$ fecal e pesquisa de substância redutora nas fezes. A intolerância à lactose é muito comum; portanto os profissionais de saúde devem estar atentos para auxiliar na definição diagnóstica e assim reduzir o trauma emocional ${ }^{12}$.

Nas falas seguintes é ressaltado pelas mães esse trauma emocional, especialmente, ao recordarem a longa trajetória vivenciada até o diagnóstico conclusivo de intolerância à lactose em seus filhos.

É muito difícil ser mãe de uma criança com esse problema, principalmente, pelo que eu tive que passar até descobrir que meu filho tinha alergia ao leite. Eu, no começo, não conseguia me dar conta do que ele tinha [...] há um ano ele vinha se queixando de dores na barriga tomava remédios indicados pela especialista.

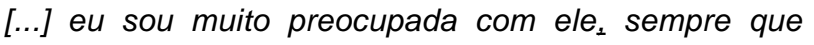
aparece alguma doença, eu fico com medo de passar por tudo de novo. (Sr. Incrível)

Até hoje ela, com dois anos, se queixa sempre de dor na barriga. (Moranguinho)

O trauma causado pelo período de sofrimento físico-emocional nas crianças e estresse emocional nos familiares, em especial nas mães, pois elas permanecem mais tempo junto de seus filhos.

Crianças e adolescentes expostos a vivências traumáticas individualmente ou em grupos, no caso desse estudo, grupo familiar, apresentam um risco maior de desenvolver diferentes problemas comportamentais, psicológicos ou neurobiológicos. Em relação aos adultos, a maioria das pessoas tem boa resposta emocional aos traumas. Provavelmente esse fato esteja relacionado à estrutura de apoio familiar e social ou devido à própria característica da personalidade ${ }^{13}$.
Novamente se aponta a responsabilidade dos profissionais de saúde, quanto à ampliação do paradigma com ênfase na mente racional, para abranger cada vez mais a mente emocional. A mente racional é mais lenta para registrar e reagir aos fatos do que a mente emocional, pois na mente emocional a ênfase está na certeza; então agimos sem parar para pensar, através de um comportamento simplificado de enfrentamento de determinadas situações. Já na mente racional, as situações são intrigantes; daí a ação ocorre somente com reflexão deliberada e analítica ${ }^{8}$.

Quanto às dificuldades apontadas pelas mães, durante a implementação do tratamento e para lidarem com seus filhos com intolerância à lactose, são praticamente as mesmas, especialmente, em relação à restrição alimentar, no fato de explicar e adaptar a criança à realidade do seu problema de saúde, pois normalmente querem comer o que as outras crianças comem e o que lhes parece gostoso.

O que torna difícil é a pouca opção para substituir a alimentação tradicional. Praticamente tudo contém leite. As bolachinhas doces, os docinhos de festa de aniversário, iogurtes. Sempre se ouviu dizer que uma criança para crescer saudável deve beber bastante leite. Então aparece essa novidade de intolerância à lactose, e fica-se sem saber como agir com isso. (Hello Kitty)

Outro aspecto identificado nos relatos dos participantes foi a atenção necessária no momento de adquirir alimentos industrializados para a criança.

Tem que ficar mais atenta, ler todos os rótulos e embalagens. Buscar alternativas para compensar os apelos das propagandas e do supermercado. (Hello Kitty)

Os rótulos de embalagens consistem numa tarefa cansativa, pois é preciso ler todos os ingredientes de todos os alimentos que serão consumidos pelas crianças com intolerância à lactose; as letras são em tamanho mínimo. Se nos rótulos existisse a informação "contém lactose ou não contém lactose", facilitaria muito o processo de viver do portador de intolerância à lactose e de sua 
família. Tal recomendação é pertinente, já que existe uma estimativa alta da população brasileira ser intolerante à lactose.

A partir do que foi exposto, evidencia-se a importância dos profissionais de saúde, em considerarem e identificarem os sinais e sintomas, ficando atentos para reconhecer uma criança com intolerância à lactose e oferecer um cuidado qualificado em relação à informação, levando em consideração suas emoções e de sua família. As famílias consideram-se, em geral, desinformadas e despreparadas para enfrentar o problema.

Ainda me considero muito mal informada. (Hello Kitty)

Eu não sabia nada sobre intolerância à lactose, só de ouvir a minha cunhada falar da minha sobrinha que é mais velha que a minha, o resto é de perguntar para os médicos onde vou e o que sei agora é o que eles me dizem. (Moranguinho)

As informações que tenho recebi dos próprios médicos que atenderam meu filho e depois disso eu comecei a ler todas as embalagens dos produtos nos supermercados e também comecei a pesquisar na internet, até mando e-mail para empresas que fabricam esses produtos sem lactose e recebo folhetos com informações. (Sr. Incrível)

Observa-se que neste estudo uma mãe, mesmo sabendo que sua filha é portadora de intolerância à lactose, reintroduz o leite ninho que contém lactose à alimentação da menina. Desta forma, sensibilizando cada vez mais a criança, que continua se queixando de dores na barriga. Assim, fica evidente a necessidade da existência de um programa de orientação e educação com vistas a uma melhor qualidade de vida da criança, o que é papel fundamental na enfermagem.

Hoje ela se alimenta com leite de soja que eu alterno com leite ninho, mas ainda se queixa de dores na barriga e às vezes as manchas reaparecem. (Hello Kitty)

As famílias destas crianças sentem falta de mais informações, sendo que estas deveriam chegar até elas em forma de propagandas, anúncios e políticas de saúde implementados pelo governo. Assim, cabe à enfermagem estimular a formação de grupos de pessoas com intolerância à lactose. Os grupos podem ser implementados em postos de saúde e instituições hospitalares para discussão dos problemas, dificuldades, dúvidas, fornecendo orientações para pessoas portadoras de intolerância à lactose e seus familiares, abrindo portas para que eles mesmos se ajudem uns aos outros, por meio do aprimoramento de suas informações e troca de idéias, melhorando sua qualidade de vida.

\section{CONSIDERAÇÕES FINAIS}

Ao estudar a experiência vivenciada por mães de crianças com intolerância à lactose, evidenciaram-se as dificuldades para cuidar e lidar com o sofrimento fisico e emocional de seu filho, especialmente pela demora da identificação da intolerância à lactose, pois esta patologia pode ser facilmente confundida com outras reações do organismo, como alergia ou sensibilidade. As mães entrevistadas se mostraram traumatizadas, em face dos problemas de saúde de seus filhos, mostrandose inseguras pela difícil trajetória que tiveram que percorrer até o descobrimento do diagnóstico de intolerância à lactose, e sentem medo pela mínima possibilidade de terem que passar, novamente, por problemas semelhantes.

Outro aspecto que gera angústia nas mães está no fato de cuidar das questões nutricionais das crianças, já que o tratamento está ligado à restrição do leite e seus derivados; porém a dúvida persiste: como fazer isso? Pois na maioria dos casos as informações fornecidas pelos profissionais de saúde não supriram as necessidades das entrevistadas, levando as mães que dispõem de uma condição socio-cultural diferenciada a buscar um conhecimento mais amplo via Internet. É neste ponto que percebo a responsabilidade dos enfermeiros, em dar oportunidade às pessoas portadoras de intolerância à lactose e seus familiares, com a formação de grupos específicos para essa clientela, nos serviços de saúde primário, secundário e terciário de atenção a saúde ou, ainda, mediante a formulação de programas e políticas de saúde para atender tal demanda reprimida. 
Recomendo, portanto, que a abordagem deste tema seja incluída e enfatizada no currículo do ensino de graduação de enfermagem, bem como nos dos demais profissionais de saúde, por ser um transtorno orgânico com relativa incidência na população. Portanto faz-se necessário que os enfermeiros e demais profissionais de saúde estejam preparados e atualizados, quanto à temática, de modo a facilitar o esclarecimento do diagnóstico e nas orientações necessárias à pessoa portadora de intolerância à lactose e seus familiares.

\section{REFERÊNCIAS}

1 Peret F, Luciano A. Terapia nutricional nas doenças do aparelho digestivo na infância. 2. ed. Rio de Janeiro: Médsi; 2001.

2 Silveira TR. et al. Manual de orientação às famílias de crianças com intolerância à lactose: Hospital das Clínicas de Porto Alegre Serviço de Pediatria Serviço de Nutrição e Dietética. Porto Alegre: Gráfica HCPA; 2000.

3 Stella R. Intolerância à lactose: nutrição. 2006. Disponível em: <http://www1.uol.com.br/cyberdiet/colunas>.

(23 mar 2006)
4 Thofhern MB. Vínculos profissionais: uma proposta para o trabalho em equipe na enfermagem [tese] Florianópolis (SC): Universidade Federal de Santa Catarina; 2005.

5 Conselho Federal de Enfermagem. Código de Ética dos Profissionais da Enfermagem. Rio de Janeiro; 24 out 2000.

6 Ministério da Saúde (BR). Resolução n. ${ }^{\circ}$ 196/96 Sobre pesquisa envolvendo seres humanos. Brasília; 1996.

7 Mesquita M. Intolerância à lactose. Disponível em: <http://www.unimed.com.br/pct> (16 fev 2006).

8 Suenaga $\mathrm{Cl}$. et al. Intolerância à lactose. Disponível em: <http://www.virtual.epm.br/material/tis/curr-bio>. (23 set 2005).

9 Goleman D. Inteligência emocional: a teoria revolucionária que redefine o que é ser inteligente. Rio de Janeiro: Editora Objetiva; 1995.

10 Waldow VR. Cuidado humano: o resgate necessário. 2. ed. Porto Alegre: Sagra Luzzatto; 1999.

11 Nettina S. Prática de enfermagem. 7.ed. Rio de Janeiro: Guanabara Koogan; 2003.

12 Silveira TR, Pretto FM. Intolerância à lactose. Associação Médica do Rio Grande do Sul; 2000. Disponível em:<http://www.medicinal.com.br/temas>. (18 mai 2005).

13 Ballone GJ. Efeitos de vivências traumáticas em crianças e adolescentes, In: PsiqWeb, Internet, 2006. Disponível em: <http://www.psiqweb.med.br> (12 fev 2006). 